\title{
Mössbauer Spectroscopic Studies of NiZn Ferrite Prepared by the Sol-Gel Method
}

\author{
Mohammad Niyaifar ${ }^{1 *}$, Hory Mohammadpour ${ }^{1}$, and Anselmo F. R. Rodriguez ${ }^{2}$ \\ ${ }^{1}$ Department of Physics, Ahvaz Branch, Islamic Azad University, Ahvaz, Iran \\ ${ }^{2}$ Universidade Federal do Acre, Centro de Ciências Biológicas e da Natureza Rio Branco, 69915-900, Brazil
}

(Received 27 June 2015, Received in final form 18 August 2015, Accepted 18 August 2015)

\begin{abstract}
This study was aimed to study the effect of $\mathrm{Zn}$ content on the hyperfine parameters and the structural variation

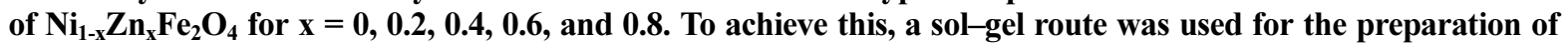
samples and the obtained ferrites were investigated by $\mathrm{X}$-ray diffraction, scanning electron microscopy, and Mössbauer spectroscopy. The formation of spinel phase without any impurity peak was identified by X-ray diffraction of all the samples. Moreover, the estimated crystallite size by $\mathrm{X}$-ray line broadening indicates a decrease with increasing $\mathrm{Zn}$ content. This result was in agreement with the scanning electron microscopy result, indicating the reduction in grain growth with further zinc substitution. The room-temperature Mössbauer spectra show that the hyperfine fields at both the A and B sites decreased with increasing Zn content; however, the rate of reduction is not the same for different sites. Moreover, the best fit parameter showed that the quadrupole splitting values of $B$ site increased from the pure nickel ferrite to the sample with $x=0.8$.
\end{abstract}

Keywords : Ni-Zn ferrite, Mössbauer spectroscopy, scanning electron microscopy, sol-gel

\section{Introduction}

NiZn ferrites have been extensively studied owing to its importance in both science and applications [1,2]. They are adjustable technological material because of their high resistivity, low dielectric losses, and high Curie temperature [3-7]. Moreover, they have diverse applications in radio frequency coils, transformer cores, microwave absorber, power transformer, magnetic recording media, and chemical sensor $[8,9]$. In recent years, significant attention has been paid to investigate the exchange interactions of these materials to explain some of their versatile magnetic properties. The magnetic properties of $\mathrm{Ni}-\mathrm{Zn}$ ferrites are strongly affected by their stoichiometric chemical composition $[10,11]$. They have a spinel configuration based on the face centered cubic lattice of the oxygen ions, with the unit cell consisting of eight formula units. $\mathrm{Zn}^{2+}$ and $\mathrm{Ni}^{2+}$ ions are known to have very strong preferences for the tetrahedral (A) and octahedral (B) sites, respectively, and are thus expected to have a cation distribution represented by $\left(\mathrm{Zn}_{\mathrm{x}} \mathrm{Fe}_{1-\mathrm{x}}\right)_{\mathrm{A}}\left[\mathrm{Ni}_{1-\mathrm{x}} \mathrm{Fe}_{1+\mathrm{x}}\right]_{\mathrm{B}} \mathrm{O}_{4}$ $[12,13]$. By referring to $\mathrm{Zn}^{2+}$ as a diamagnetic ion, the $\mathrm{Zn}$

(C)The Korean Magnetics Society. All rights reserved.

*Corresponding author: Tel: +986134435288

Fax: +989351055293, e-mail: md.niyaifar@gmail.com substitution in $\mathrm{NiFe}_{2} \mathrm{O}_{4}$ leads to an unequal reduction in magnetic hyperfine interaction of both the $\mathrm{A}$ and $\mathrm{B}$ sublattices.

Therefore, it would be interesting to compare the rate of decrease in the magnetic hyperfine interaction of each sublattice and also investigate the effect of $\mathrm{Zn}$ ion on the structural deformations. The $\mathrm{Ni}-\mathrm{Zn}$ ferrite has already been prepared by methods such as mechanochemical alloying [14], coprecipitation [15, 16], hydrothermal [1719], microwave [20], sol-gel [21-24], citrate precursor $[25,26]$, nitrate- and reverse micelle [27]. However, these materials are sensitive, and their magnetic properties directly depend on the cation distribution and the particle sizes, which are affected by the method of preparation.

Thus, the sol-gel route was selected to prepare a series of $\mathrm{Ni}_{1-\mathrm{x}} \mathrm{Zn}_{\mathrm{x}} \mathrm{Fe}_{2} \mathrm{O}_{4}(\mathrm{x}=0,0.2,0.4,0.6$, and 0.8$)$, because of its cost-effectiveness and simplicity avoid compounds with nonstoichiometric chemical composition and high porosity, which may be obtained by other methods. By considering ${ }^{57} \mathrm{Fe}$ Mössbauer spectroscopy as an important probe to study of the hyperfine parameters, the structural changes and hyperfine interaction were studied.

\section{Material and Methods}

$\mathrm{Ni}_{1-\mathrm{x}} \mathrm{Zn}_{\mathrm{x}} \mathrm{Fe}_{2} \mathrm{O}_{4},(\mathrm{x}=0,0.2,0.4,0.6$, and 0.8$)$ were syn- 
thesized by the sol-gel auto-combustion method. The starting materials were $\mathrm{Fe}\left(\mathrm{NO}_{3}\right)_{3} \cdot 9 \mathrm{H}_{2} \mathrm{O}, \mathrm{Ni}\left(\mathrm{NO}_{3}\right)_{2} \cdot 6 \mathrm{H}_{2} \mathrm{O}$, $\mathrm{Zn}\left(\mathrm{NO}_{3}\right)_{2} \cdot 6 \mathrm{H}_{2} \mathrm{O}$, and citric acid. An aqueous solution of metal ions and chelating agent were prepared in distilled water. The molar amount of metal nitrate to citric acid was $1: 1$. The $\mathrm{pH}$ value was adjusted to 7 by dropwise addition of ammonia solution, and the solution was evaporated on a hot plate at $80^{\circ} \mathrm{C}$ to form a condensed gel. Then, the gel was placed in a laboratory oven at 200 ${ }^{\circ} \mathrm{C}$. The prepared powders, with different stoichiometries were calcined at $1000^{\circ} \mathrm{C}$ to obtain the samples. X-ray diffraction was performed with a $\mathrm{Cu} \mathrm{K} \alpha$ radiation (the model). The microstructures were characterized using a scanning electron microscope for estimating the grain size. Furthermore, Mössbauer spectra of the samples were recorded using a Mössbauer spectrometer (Model CM 1101 Russia) with velocity in range of -10 to $10 \mathrm{~mm} / \mathrm{s}$ under constant acceleration at room temperature. The $\gamma$ rays were provided by a ${ }^{57} \mathrm{Co}$ source in $\mathrm{Rh}$ matrix. The Mössbauer spectra were analyzed by the Mossfit software.

\section{Result and Discussions}

\subsection{Structural analysis}

The powder XRD patterns of $\mathrm{Zn}_{\mathrm{x}} \mathrm{Ni}_{1-\mathrm{x}} \mathrm{Fe}_{2} \mathrm{O}_{4}$ for $\mathrm{x}=0.0$, $0.2,0.4,0.6$, and 0.8 exhibit a single-phase cubic spinel structure. Fig. 1 shows the XRD pattern of all the samples. The average crystallite size of the spinel phase was estimated from the broadening of the XRD peaks using the Scherrer's equation. The crystallite size of samples varies from $82 \mathrm{~nm}$ for sample $\mathrm{x}=0.0$ to $63 \mathrm{~nm}$ and $\mathrm{x}$ $=0.8$. The lattice constants (a) shows a variation in

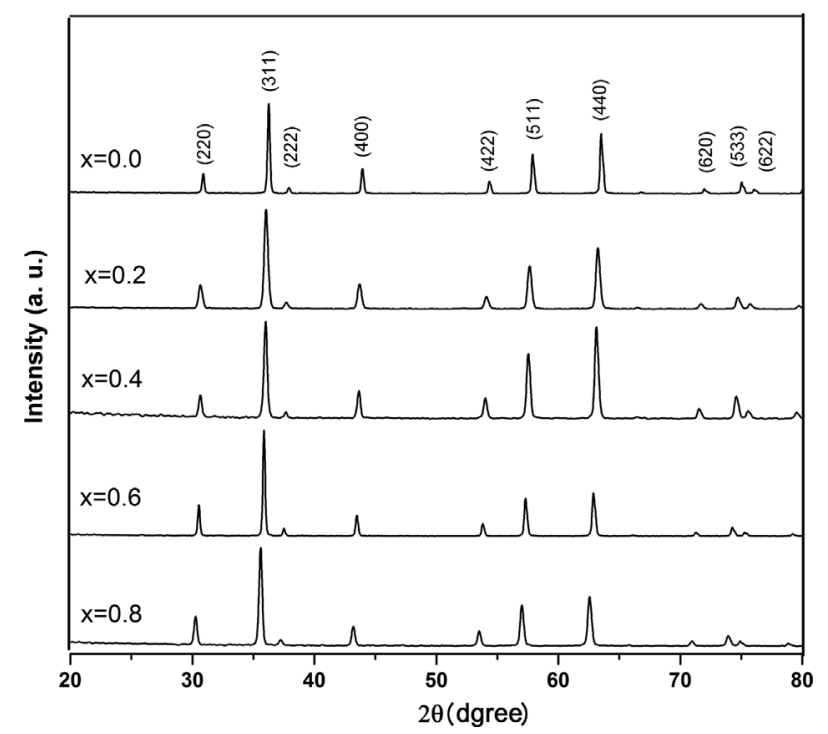

Fig. 1. X-ray diffraction patterns of the samples $\mathrm{Ni}_{1-\mathrm{x}} \mathrm{Zn}_{\mathrm{x}} \mathrm{Fe}_{2} \mathrm{O}_{4}$.

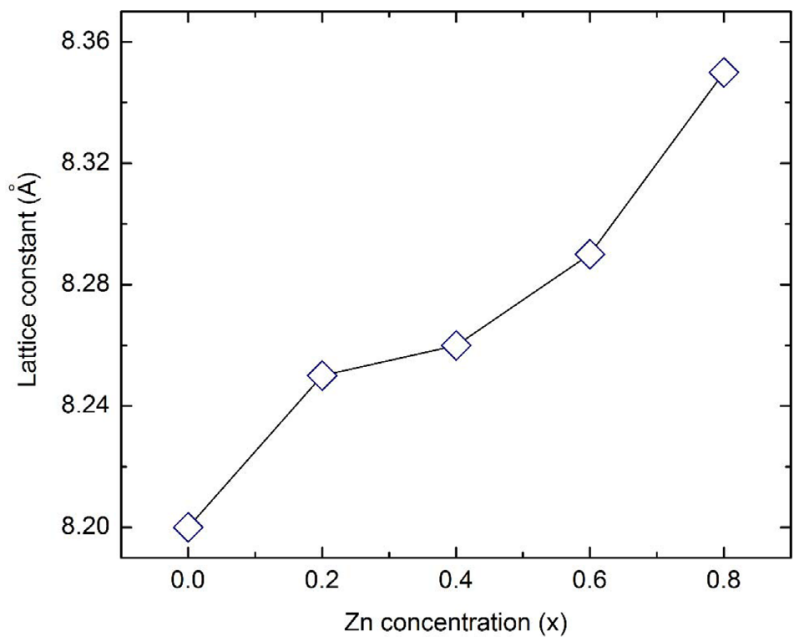

Fig. 2. (Color online) The variation of the lattice constant of $\mathrm{Ni}_{1-\mathrm{x}} \mathrm{Zn}_{\mathrm{x}} \mathrm{Fe}_{2} \mathrm{O}_{4}$ as a function of $\mathrm{Zn}$ content.

Table 1. The lattice constant of $\mathrm{Ni}_{1-\mathrm{x}} \mathrm{Zn}_{\mathrm{x}} \mathrm{Fe}_{2} \mathrm{O}_{4}(\mathrm{x}=0.0,0.2$, $0.4,0.6$ and 0.8 )

\begin{tabular}{cc}
\hline \hline Composition & $\mathrm{a}(\AA)$ \\
$\mathrm{Ni}_{1-\mathrm{x}} \mathrm{Zn}_{\mathrm{x}} \mathrm{Fe}_{2} \mathrm{O}_{4}$ & \\
$\mathrm{x}=0.0$ & $8.20 \pm 0.01$ \\
$\mathrm{x}=0.2$ & $8.25 \pm 0.01$ \\
$\mathrm{x}=0.4$ & $8.26 \pm 0.01$ \\
$\mathrm{x}=0.6$ & $8.29 \pm 0.01$ \\
$\mathrm{x}=0.8$ & $8.35 \pm 0.01$ \\
\hline
\end{tabular}

$\mathrm{Zn}_{\mathrm{x}} \mathrm{Ni}_{1-\mathrm{x}} \mathrm{Fe}_{2} \mathrm{O}_{4}(0.0 \leq \mathrm{x} \leq 0.8)$, as shown in Fig. 2, exhibiting an increase with increasing $\mathrm{Zn}$ content (Table 1). This increase can be expected in view of the fact that $\mathrm{Ni}^{+2}$ with smaller radius is substituted by $\mathrm{Zn}^{+2}$ with a larger ionic radius [28, 29].

\subsection{Morphological Analysis}

Fig. 3 shows the typical SEM pictures for samples $\mathrm{x}=$ $0.0,0.4$, and 0.8 , indicating that the grains gradually decreases with increasing $\mathrm{Zn}$ content $(\mathrm{x})$, which is in accordance with the estimated average particle size obtained by the XRD results. According to the earlier reports, the increase in the crystallite size can be attributed to the increase in the enthalpy of formation. The enthalpy of formation of Nickel ferrite $(-1.22 \mathrm{kcal} / \mathrm{mol})$ is more than that of Zinc ferrite $(-2.67 \mathrm{kcal} / \mathrm{mol})$ [30]. Therefore, the formation of Zinc ferrite is more exothermic as compared to the formation of nickel ferrite. In fact, the molecular concentration of the crystal on the surface during the growth process is the most important parameter, affecting the crystal growth [31]. By zinc doping, more heat was liberated, and this extra heat decreased the molecular 

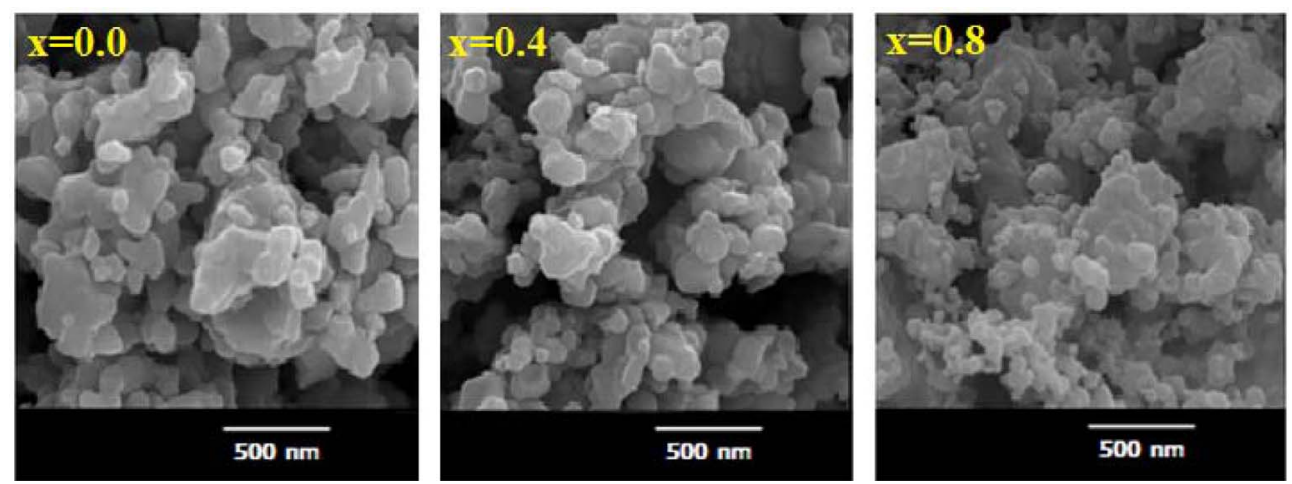

Fig. 3. (Color online) The scanning electron microscopic images of $\mathrm{Ni}_{1-\mathrm{x}} \mathrm{Zn}_{\mathrm{x}} \mathrm{Fe}_{2} \mathrm{O}_{4}(\mathrm{x}=0.0,0.4,0.8)$.

concentration at the crystal surface by increasing the surface temperature and hence preventing the crystal growth [32]. These results indicate that the addition of $\mathrm{Zn}$ obstructs the crystal growth in $\mathrm{Ni}-\mathrm{Zn}$ ferrites.

\subsection{Mössbauer analysis}

The room-temperature Mössbauer spectra of $\mathrm{Zn}_{\mathrm{x}} \mathrm{Ni}_{1-\mathrm{x}} \mathrm{Fe}_{2} \mathrm{O}_{4}$ for $\mathrm{x}=0.0,0.2,0.4,0.6$, and 0.8 are shown in Fig. 4. The dots in the figure represent the experimental data and solid lines through the data points are the least-square fitting. Table 2 summarizes various Mössbauer refined parameters. The Mössbauer spectra of the samples with $\mathrm{x}$ $=0.0,0.2$, and 0.4 are fitted with two magnetic sextets referring to the $\mathrm{A}$ and $\mathrm{B}$ sites, whereas for the sample with $\mathrm{x}=0.6$, an extra doublet appeared in addition to those assigned to the A and B sites. Moreover, the Mössbauer spectrum of the sample with $\mathrm{x}=0.8$ shows a clear central doublet and a weak singlet (Fig. 4).

The quadrupole splitting (QS) for the sample with $\mathrm{x}=0$ shows a larger value at the octahedral site compared to that at the tetrahedral site, attributed to the difference between the cubic symmetry at the A site and trigonal symmetry at the B site. ${ }^{57} \mathrm{Fe}$ nucleus in a cubic point symmetry and is known to experience no electric field gradient (EFG), and thus zero QS. While at the B site, the trigonal symmetry leads to a nonspherical distribution of charge on the next nearest ions, generating two opposing trigonal fields. Therefore, for ${ }^{57} \mathrm{Fe}$ nucleus, a net EFG appears at the B site, causing a nonzero QS [33]. The magnetic hyperfine fields for sample with $\mathrm{x}=0.0$ are $\mathrm{H}_{\mathrm{hf}}(\mathrm{A})=48.5$ and $\mathrm{H}_{\mathrm{hf}}(\mathrm{B})=52.9$, which are comparable to those reported by De Marco et al. for the pure nickel ferrite [34].

To explain the difference between $\mathrm{H}_{\mathrm{hf}}(\mathrm{A})$ and $\mathrm{H}_{\mathrm{hf}}(\mathrm{B})$, it is worthy to note that the magnetic hyperfine interaction not only depends on the different covalences of the $\mathrm{Fe}-\mathrm{O}$ bond at the A and $\mathrm{B}$ sites, but also originates from the

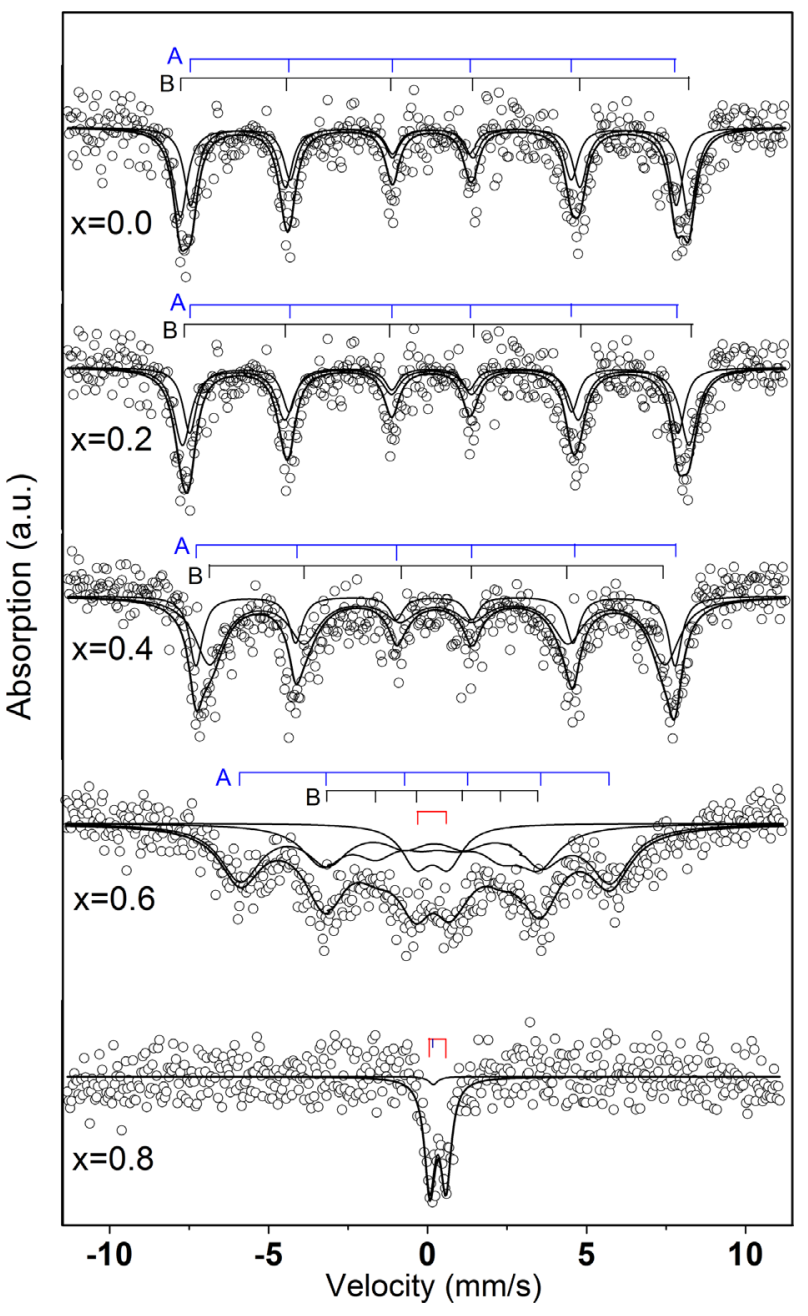

Fig. 4. (Color online) The Mössbauer spectra of $\mathrm{Ni}_{1-\mathrm{x}} \mathrm{Zn}_{\mathrm{x}} \mathrm{Fe}_{2} \mathrm{O}_{4}$ $(0 \leq \mathrm{x} \leq 0.8)$.

average magnetization of each sublattice. In fact the average nuclear magnetic field for $\mathrm{Fe}^{3+}$ ions is proportional to the average magnetization of the sublattice, which changes with the number of magnetic bonds $[35,36]$. 
Table 2. The Mössbauer hyperfine fitting parameters of $\mathrm{Ni}_{1-\mathrm{x}} \mathrm{Zn}_{\mathrm{x}} \mathrm{Fe}_{2} \mathrm{O}_{4}(\mathrm{x}=0.0,0.2,0.4,0.6$ and 0.8$)$

\begin{tabular}{|c|c|c|c|c|c|c|}
\hline $\begin{array}{c}\text { Composition } \\
\mathrm{Ni}_{1-\mathrm{x}} \mathrm{Zn}_{\mathrm{x}} \mathrm{Fe}_{2} \mathrm{O}_{4}\end{array}$ & site & IS (mm/s) & $\mathrm{QS}(\mathrm{mm} / \mathrm{s})$ & $\mathrm{H}_{\mathrm{hf}}(\mathrm{T})$ & $\mathrm{W}(\mathrm{mm} / \mathrm{s})$ & Area $(\%)$ \\
\hline \multirow{2}{*}{$x=0.0$} & A & $0.11 \pm 0.01$ & $-0.24 \pm 0.02$ & $48.5 \pm 0.06$ & $0.52 \pm 0.05$ & 40.47 \\
\hline & B & $0.32 \pm 0.03$ & $-0.23 \pm 0.02$ & $52.5 \pm 0.08$ & $0.43 \pm 0.04$ & 59.53 \\
\hline \multirow{2}{*}{$x=0.2$} & A & $0.14 \pm 0.02$ & $-0.15 \pm 0.03$ & $47.8 \pm 0.09$ & $0.52 \pm 0.08$ & 49.71 \\
\hline & B & $0.18 \pm 0.02$ & $-0.13 \pm 0.04$ & $48.2 \pm 0.09$ & $0.65 \pm 0.07$ & 50.29 \\
\hline \multirow{2}{*}{$x=0.4$} & A & $0.23 \pm 0.01$ & $-0.02 \pm 0.03$ & $45.3 \pm 0.11$ & $0.5 \pm 0.02$ & 31.68 \\
\hline & B & $0.28 \pm 0.02$ & $0.0 \pm 0.05$ & $41.2 \pm 0.17$ & $1.13 \pm 0.08$ & 68.32 \\
\hline \multirow{3}{*}{$x=0.6$} & A & $0.14 \pm 0.03$ & $-0.28 \pm 0.05$ & $36.1 \pm 0.18$ & $1.5 \pm 0.09$ & 50.43 \\
\hline & B & $0.29 \pm 0.06$ & $0.3 \pm 0.08$ & $21.1 \pm 0.09$ & $1.5 \pm 0.07$ & 34.47 \\
\hline & doublet (B) & $0.21 \pm 0.04$ & $1.2 \pm 0.05$ & - & $1.3 \pm 0.08$ & 15.10 \\
\hline \multirow{2}{*}{$\mathrm{x}=0.8$} & doublet (B) & $0.32 \pm 0.08$ & $0.5 \pm 0.01$ & - & $0.39 \pm 0.02$ & 96.75 \\
\hline & singlet (A) & $0.18 \pm 0.09$ & - & - & $0.35 \pm 0.08$ & 3.25 \\
\hline
\end{tabular}

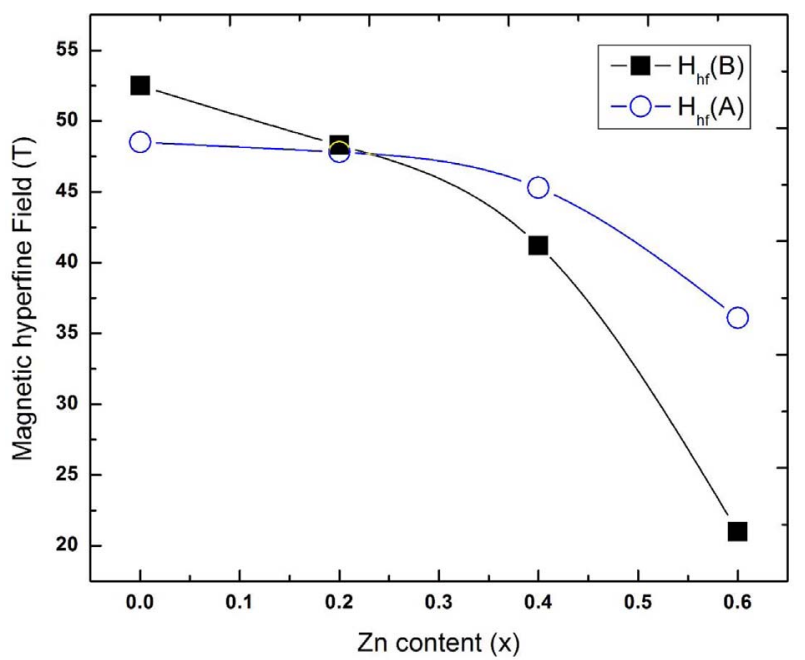

Fig. 5. (Color online) The variation of magnetic hyperfine field at octahedral and tetrahedral sites of $\mathrm{Ni}_{1-x} \mathrm{Zn}_{\mathrm{x}} \mathrm{Fe}_{2} \mathrm{O}_{4}$ as a function of $\mathrm{Zn}$ content.

For sample with $\mathrm{x}=0.0$, the iron ions at the $\mathrm{B}$ site have all its intersublattice magnetic bonds with $\mathrm{Fe}^{3+}$ ions of $\mathrm{A}$ site $\left(\mathrm{Fe}_{\mathrm{B}}^{3+}-\mathrm{O}^{2-}-\mathrm{Fe}_{\mathrm{A}}^{3+}\right)$, whereas the presence of the weaker $\mathrm{Fe}^{3+}-\mathrm{O}^{2-}-\mathrm{Ni}^{2+}$ magnetic bonds at the $\mathrm{A}$ site [37] make the tetrahedral magnetization smaller than that of the octahedral site, resulting in $\mathrm{H}_{\mathrm{hf}}(\mathrm{B})>\mathrm{H}_{\mathrm{hf}}(\mathrm{A})$. For the samples with $\mathrm{x}>0$, the obtained parameters show that by increasing the $\mathrm{Zn}$ content, $\mathrm{H}_{\mathrm{hf}}(\mathrm{B})$ decreases more rapidly than $\mathrm{H}_{\mathrm{hf}}(\mathrm{A})$ and crossovers at $\mathrm{x}=0.2$ (Fig. 5).

To explain the rate of decrease in the magnetic hyperfine interactions of each site, it should be noted that by increasing the $\mathrm{Zn}$ content, some of the magnetic bonds at the $\mathrm{B}$ site vanished by changing $\mathrm{Fe}_{\mathrm{B}}-\mathrm{O}-\mathrm{Fe}_{\mathrm{A}}$ to $\mathrm{Fe}_{\mathrm{B}}-$ $\mathrm{O}-\mathrm{Zn}_{\mathrm{A}}$. However, the replacement of $\mathrm{Ni}_{\mathrm{B}}^{2+}$ with $\mathrm{Fe}_{\mathrm{B}}^{2+}$ at the $\mathrm{B}$ site increases the strength of magnetic bond for

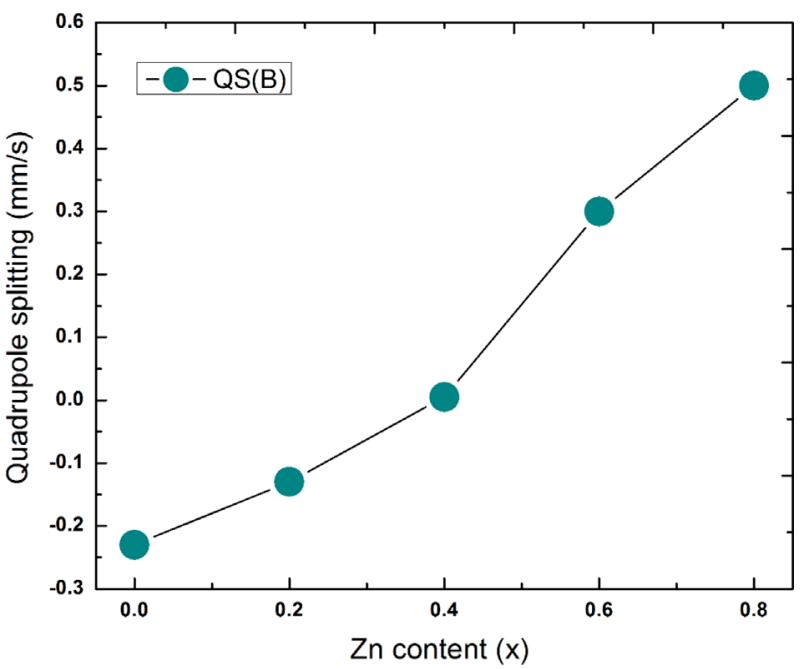

Fig. 6. (Color online) The variation of quadrupole splitting at octahedral and tetrahedral sites of $\mathrm{Ni}_{1-\mathrm{x}} \mathrm{Zn}_{\mathrm{x}} \mathrm{Fe}_{2} \mathrm{O}_{4}$ as a function of $\mathrm{Zn}$ content.

iron ions at the A site. Therefore, the magnetization at the A site increases, whereas it decrease for the $B$ site, indicating that the rate of reduction in magnetic hyperfine interaction at the $\mathrm{A}$ site is less than that of the $\mathrm{B}$ site.

Moreover, the increase in the line broadening at the $\mathrm{B}$ site was observed for samples $0.2<\mathrm{x} \leq 0.6$. This is attributed to the effect of spin canting at the $B$ site because of diamagnetic substitution at the A site [38, 39].

The QS is negligible at the A site by increasing $\mathrm{Zn}$ content. This is a consequence of the cubic symmetry at the A site which is remained unchanged by the replacement of $\mathrm{Fe}^{3+}$ with $\mathrm{Zn}^{2+}$ ions. However, the QS considerably increased at the $\mathrm{B}$ site by increasing $\mathrm{Zn}$ content (Fig. 6), which can be explained by considering the shift of the oxygen ions at the nearest neighbors of the 
B site from the ideal octahedral symmetry. This distortion is because of the replacement of the small $\mathrm{Fe}^{3+}$ ions $(0.64$ $\AA)$ by the larger $\mathrm{Zn}^{2+}$ ions $(0.74 \AA)$ at the tetrahedral sites, increasing EFG at the B site. The effect of octahedron distortion by $\mathrm{Zn}$ substitution can be attributed to the change in the $u$ parameter of $\mathrm{NiFe}_{2} \mathrm{O}_{4}(0.382)$ to that of $\mathrm{ZnFe}_{2} \mathrm{O}_{4}(0.385)$ [40, 41]. In the previous study on the variation of QS for different spinel ferrites, it is proposed that the change in the QS is proportional to the u parameter [42]. Therefore, the monotonic increase in the QS in $\mathrm{Ni}_{1-\mathrm{x}} \mathrm{Zn}_{\mathrm{x}} \mathrm{Fe}_{2} \mathrm{O}_{4}$ system is attributed to increase in the $\mathrm{u}$ parameter.

For the spectrum of the sample with $\mathrm{x}=0.6$, acceptable data fitting was obtained when it is assumed to be the superposition of one paramagnetic doublet and two broadened sextets. The presence of this doublet can be assigned to the iron ions at the $\mathrm{B}$ site, which are surrounded by $\mathrm{Zn}^{2+}$ diamagnetic ions at the tetrahedral site. The $\mathrm{Zn}^{2+}$ substitution at the A site induces a relaxation effect for iron ions at both the sites owing to the weakening of A-B exchange coupling, thus broadening at the $\mathrm{A}$ and $\mathrm{B}$ sites. For sample with $\mathrm{x}=0.8$, the presence of a central quadrupole doublet with no signature of sextets indicates the disappearance of magnetic ordering in both the sites.

In $\mathrm{Zn}_{0.8} \mathrm{Ni}_{0.2} \mathrm{Fe}_{2} \mathrm{O}_{4}$, approximately most of $\mathrm{Fe}^{3+}$ ions occupy the B-sites, where a trigonal field is present, causing an $\mathrm{EFG}$ at the $\mathrm{Fe}^{3+}$ nucleus, leading to a quadrupole doublet. Moreover, a small percentage of $\mathrm{Fe}^{3+}$ ions at the A sites do not experience any EFG, because of the cubic symmetry of this site. Therefore, the spectrum for the sample with $\mathrm{x}=0.8$ was a superposition of a singlet arising from the A site and a doublet corresponding to the B site iron.

\section{Conclusion}

In summary, a simple sol-gel method was applied to the synthesis $\mathrm{Ni}_{1-\mathrm{x}} \mathrm{Zn}_{\mathrm{x}} \mathrm{Fe}_{2} \mathrm{O}_{4}(\mathrm{x}=0.0,0.2,0.4,0.6$, and $0.8)$ system. The XRD patterns indicate the formation of a well crystalline single cubic structure phase for all samples, which were annealed at $1000^{\circ} \mathrm{C}$ for $2 \mathrm{~h}$. The corresponding average crystallite size ranged from 63 to $82 \mathrm{~nm}$ by varying the components $\mathrm{x}$ from 0.0 to 0.8 . The SEM images showed that the grain growth was obstructed by the presence of zinc. The decrease in the grain size was assigned to the larger enthalpy of formation of nickel ferrite compared to that of zinc ferrite. The room-temperature Mössbauer measurement shows that by increasing the zinc content the magnetic hyperfine at the octahedral site decreased more rapidly than that of the tetrahedral site. The variation in the $\mathrm{H}_{\mathrm{hf}}$ with zinc content is explain- ed based on the strength of magnetic bonds and superexchange interaction, which depended on the replacement of $\mathrm{Ni}^{+2}$ by $\mathrm{Zn}^{2+}$ ions and the migration of iron ions from the A site to B site. Furthermore, the spin-canting effect at the $\mathrm{B}$ site because of diamagnetic $\mathrm{Zn}^{2+}$ ions at $\mathrm{A}$ site was used to describe the observed increment in line broadening of the B site-sextet for samples $0.2>\mathrm{x} \geq 0.6$. The replacement of the $\mathrm{Fe}^{3+}$ ions by the larger $\mathrm{Zn}^{2+}$ ions at the tetrahedral sites also increased the QS of the octahedral site, attributed to the change in the oxygen parameter, thus increasing the EFG at the B site.

\section{Acknowledgements}

The authors acknowledge the support from Ahvaz Branch, Islamic Azad University through Grant No. 52323920218004.

\section{References}

[1] M. M. Mallapur, P. A. Shaikh, R. C. Kambale, H. V. Jamadar, P. U. Mahamuni, and B. K. Chougule, J. Alloys Compd. 479, 797 (2009).

[2] M. Ishaque, M. U. Islam, M. A. Khan, I. Z. Rahman, A. Genson, and S. Hampshire, Physica B 405, 1532 (2010).

[3] R. Valenzuela, Phys. Res. Int. 2012, 1 (2012).

[4] P. Yadoji, R. Peelamedu, D. Agrawal, and R. Roy, Mater. Sci. Eng. B 98, 269 (2003).

[5] A. M. Shaikh, C. M. Kanmadi, and B. K. Chougule, J. Mater. Chem. Phys. 93, 548 (2005).

[6] T. Nakamura, J. Magn. Magn. Mater. 168, 285 (1997).

[7] T. Tsutaoka, J. Appl. Phys. 93, 2789 (2003).

[8] M. F. F. Lelis, A. O. Porto, C. M. Gonçalves, and J. D. Fabris, J. Magn. Magn. Mater. 278, 263 (2004).

[9] C. M. B. Henderson, J. M. Charnock, and D. A. Plant, J. Phys.: Condens. Matter 19, 076214/1 (2007).

[10] M. M. Rashad, E. M. Elsayed, M. M. Moharam, and R. M. Abou-Shahba, A. E. Saba, J. Alloys. Compd. 486, 759 (2009).

[11] M. Atif, M. Nadeem, R. Grössinger, and R. Sato Turtelli, J. Alloys Compd. 509, 5720 (2011).

[12] A. S. Fawzi, A. D. Sheikh, and V. L. Mathe, J. Alloys Compd. 502, 231 (2010).

[13] J. M. Daniels and A. Rosencwaig, Can. J. Phys. 48, 381 (1970).

[14] M. Jalaly, M. H. Enayati, P. Kameli, and F. Karimzadeh, Physica B 405, 507 (2010).

[15] Y. Qu, H. Yang, N. Yang, Y. Fan, H. Zhu, and G. Zou, J. Mater. Lett. 60, 3548 (2006).

[16] K. Maaz, S. Karim, A. Mumtaz, S. K. Hasanain, J. Liu, and J. L. Duan, J. Magn. Magn. Mater. 321, 1838 (2009).

[17] X. Li and G. Wang, J. Magn. Magn. Mater. 321, 1276 (2009) 
[18] X. Li, Q. Li, Z. Xia, and W. Yan, J. Alloys Compd. 458, 558 (2008).

[19] H. W. Wang and S. C. Kung, J. Magn. Magn. Mater. 270, 230 (2004).

[20] V. K. Sankaranarayanan and C. Sreekumar, Curr. Appl. Phys. 3, 205 (2003).

[21] A. Kumar, M. C. Varma, C. L. Dube, K. H. Rao, and S. C. Kashyap, J. Magn. Magn. Mater. 320, e370 (2008).

[22] H. E. Zhang, B. F. Zhang, G. F. Wang, X. H. Dong, and Y. Gao, J. Magn. Magn. Mater. 312, 126 (2007).

[23] S. Yan, J. Geng, L. Yin, and E. Zhou, J. Magn. Magn. Mater. 277, 84 (2004).

[24] S. Zahi, M. Hashim, and A. R. Daud, J. Magn. Magn. Mater. 308, 177 (2007).

[25] A. Verma, T. C. Goel, R. G. Mendiratta, and P. Kishan, J. Magn. Magn. Mater. 208, 13 (2000).

[26] A. Verma, O. P. Thakur, C. Prakash, T. C. Goel, and R. G. Mendiratta, Mater. Sci. Eng. B 116, 1 (2005).

[27] S. Thakar, S. C. Katyal, and M. Singh, J. Magn. Magn. Mater. 321, 1 (2009).

[28] R. D. Shannon and C. T. Prewitt, Acta Cryst. B 26, 1046 (1970).

[29] I. H. Gul, W. Ahmwd, and A. Maqsood, J. Magn. Magn. Mater. 320, 270 (2008).

[30] A. Navrotsky and O. J. Kleppa, J. Inorg. Nucl. Chem. 30,
479 (1968).

[31] R. F. Strickland Constable, Kinetics and Mechanism of Crystallization, Academic, New York (1968).

[32] C. Upadhyay and H. C. Verma, J. Appl. Phys. 95, 5751 (2004).

[33] J. Smit, F. K. Lotgering, and R. P. Van Stapele, J. Phys. Soc. Japan Suppl. 17, 268 (1962).

[34] M. De Marco, X. W. Wang, R. L. Snyder, J. Simmins, S. Bayya, and M. White, J. Appl. Phys. 73, 6287 (1993).

[35] D. E. Nagle, H. Frauenfelder, R. D. Taylor, D. R. F. Cochran, and B. T. Matthias, Phys. Rev. Lett. 5, 364 (1960).

[36] R. E. Watson and A. J. Freeman, Phys. Rev. 123, 2027 (1961).

[37] S. Geller, H. J. Williams, R. C. Sherwood, and G. P. Espinosa, J. Phys. Chem. Solids 23, 1525 (1962).

[38] P. G. Bercoff and H. R. Bertorello, J. Magn. Magn. Mater. 213, 56 (2000).

[39] G. F. Dionne, J. Appl. Phys. 41, 4874 (1970).

[40] S. I. Youssef, M. G. Natera, R. J. Begum, B. S. Srinivasan, and N. S. Satya Murthy, J. Phys. Chem. Solids 30, 1941 (1969).

[41] R. Ingalls, Phys. Rev. 133, A787 (1964).

[42] C. M. Yagnik and H. B. Mathur, Mol. Phys. 16, 625 (1969). 